\title{
What are Users' Perceptions of the Hospital Courtyard Garden and How Satisfied are they with it?
}

\author{
Madihah Mat Idris ${ }^{1}$, Magda Sibley ${ }^{2}$ \\ ${ }^{1}$ School of Architecture, Faculty of Social Science, \\ University of Sheffield, United Kingdom \\ 2 Welsh School of Architecture, \\ Cardiff University, United Kingdom \\ madihah.usim@gmail.com, SibleyM@cardiff.ac.uk
}

\begin{abstract}
Since the 1970s, courtyard gardens with diverse scales and design configurations have been introduced in the planning of Malaysian public hospitals to enhance users' experiences. However, these have never been systematically evaluated to understand of how they perform and what improvements can be made to them to increase their responsiveness to users' needs and inform the practice of both hospital designers and managers. This paper presents the results of fieldwork conducted in a large central courtyard in a Malaysian public hospital. Interview surveys and field measurements were conducted to provide a new understanding of users' perceptions of the various physical and environmental attributes and their satisfaction levels with them.

Keywords: Hospital courtyard garden; perceptions; experiences; level of satisfaction.

eISSN 2514-751X @ 2019. The Authors. Published for AMER ABRA CE-Bs by e-International Publishing House, Ltd., UK. This is an open-access article under the CC BY-NC-ND license (http://creativecommons.org/licenses/bync-nd/4.0/). Peer-review under responsibility of AMER (Association of Malaysian Environment-Behaviour Researchers), ABRA (Association of Behavioural Researchers on Asians) and cE-Bs (Centre for EnvironmentBehaviour Studies), Faculty of Architecture, Planning \& Surveying, Universiti Teknologi MARA, Malaysia. DOI: https://doi.org/10.21834/aje-bs.v4i13.348
\end{abstract}




\subsection{Introduction}

The quality of a hospital's architectural design can contribute to enhance a health delivery system as well as facilitate faster patients' recovery by delivering a healthy and comfortable environment for the end users. Extended waiting time can also cause patients inconvenience, particularly when waiting for a doctor's consultation and collect prescriptions at the hospital pharmacy. Therefore, the provision of outdoor space in the form of a Hospital Courtyard Garden (HCG) can be highly beneficial to both patients and their relatives or friends. This is because of its potential in providing a conducive outdoor environment for relaxation and social interaction for hospital users, away from the congested waiting areas inside the hospital. Furthermore, hospital employees could also benefit from the provision of a courtyard garden as it offers them with an outdoor space where they could escape for a while from the stark and sterile hospital environment and revitalise their minds from extended hours of working indoors.

Although the inclusion of diverse categories of courtyard designs in the planning of hospital buildings in Malaysia goes back as far as the 1970s (Mat Idris, Sibley and Hadjri, 2018a), there have been no systematic assessments conducted about their designs. As part of an ongoing POE study, this paper aims to: (a) provide an understanding of the perception of users pertaining to the physical and microclimatic conditions of a large central courtyard garden in a case study hospital in Malaysia; (b) evaluate users' experiences of the HCG; and (c) measure the level of users' satisfaction with the HCG.

\subsection{Literature Review}

\subsection{Post Occupancy Evaluation (POE)}

POE is a methodical and laborious procedure of evaluating buildings that are occupied for a period of time (Preiser, 1995). POE functions to establish an understanding of the occupants' behaviours, perceptions, and satisfaction level. POE allows evaluation of the indoor environment of the building. Moreover, it could also be extended and applied to assess the outdoor environment (e.g. public squares, parks, plazas, rooftop gardens and courtyard gardens) of a specific building or urban setting (Cooper Marcus and Francis, 1998; Davis, 2011; Cooper Marcus and Sachs, 2014).

POE is crucial in the planning and development procedure of government and public buildings in Malaysia to guarantee the facilities are properly managed and maintained (Nawawi and Khalil, 2008). The Malaysian Ministry of Health (MOH), in collaboration with the Medical and Health Branch of the Public Work Department in Malaysia, started the POE of a hospital building in 1997. This initiative was primarily focused on inpatient and outpatient hospital facilities including wards, clinics and laboratories (Mastor and Ibrahim, 2010; Mohd Nawawi, 2011).

However, there is no data on systematic evaluation using POE carried out by governmental bodies or scholars particularly on the courtyard gardens of public hospitals, which are visited by various categories of users (i.e. patients, staff and visitors). Only one 
POE study could be found and which was carried out in the paediatric wards of eight hospitals in Malaysia to examine the physical design and healing environment in the wards. Abbas and Ghazali (2012) reported that most of the patients were dissatisfied with the lack of access to the natural environment in the paediatric wards. Nevertheless, this study did not evaluate the users' perceptions and experiences with the physical and microclimatic conditions of the outdoor gardens in hospitals.

\subsection{Evaluation studies on users' feedback on outdoor gardens in healthcare facilities}

The Malaysian Ministry of Health ( $\mathrm{MOH}$ ) has included the insertion of a 'healing gardens' as a requirement for the design of public hospitals in Malaysia, owing to the positive effects of nature on well-being. This has been established in order to promote healthier environments in hospitals (Ibrahim et al., 2015). According to Almhafdy et al. (2013), various forms of a courtyard garden with diverse design configuration such as enclosed and semi-enclosed courtyard garden were integrated in many hospitals in Malaysia. However, the quality and success of the HCGs in Malaysia have not been methodically examined so far. Many previous studies focused on POE and the assessment of users' feedback pertaining to outdoor gardens in healthcare facilities were performed in Western nations (Sachs, 1999; Cooper Marcus and Barnes, 1995; Whitehouse et al., 2001; Sherman et al., 2005; Naderi and Shin, 2008; Davis, 2011; Shukor, 2012; Pasha, 2013; Butterfield, 2014). Comprehensive comparative POE investigations of HCG with diverse design configurations and concepts are therefore lacking. Only two studies could be found and which included the examination users' feedback and observation on the quality of the outdoor gardens in hospitals in Malaysia: one focusing on childrens' perceptions of an outdoor garden in a paediatric hospital (Said et al., 2005), the other one focusing on the implementation of Roger Ulrich's Theory of Supportive Garden Design to outdoor gardens in two Malaysian hospitals (Ibrahim et al., 2015). Thus, the current POE study on the quality of courtyard gardens in hospitals in the tropical climate of Malaysia and the way they are used and perceived by various building users addresses a real research gap.

\subsection{Methodology}

\subsection{Site description}

Hospital $(\mathrm{H} 1)$ is a specialist public hospital, which has ten floors with the capacity to accommodate 704 beds. The site plan of the hospital (H1) was developed along a NorthSouth orientation to reduce sunlight penetration from the East and West, which should enhance thermal conditions in both outdoor and indoor spaces (Fig. 1 (a)). The area of the HCG is 2,100 sqm and has well-matured plants and wide-ranging canopy trees that offer shade to the ground area and shields from direct light penetration to the indoor spaces surrounding the courtyard garden (See Fig.1 (b)).

The large enclosed HCG provided light, airy and spacious areas for social interaction for patients, staff and visitors. It is positioned on level 2 and is accessed via the main hospital 
street designed street which links the courtyard to other key public and outpatient facilities such as the cafeteria, the prayer room, the visitor centre and public toilets (See Fig. 2)

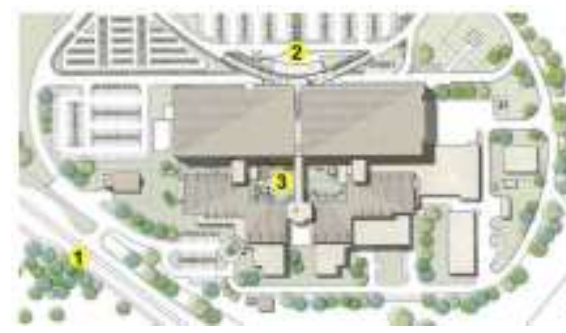

(a)

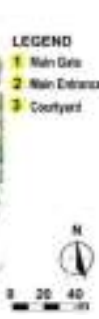

(b)

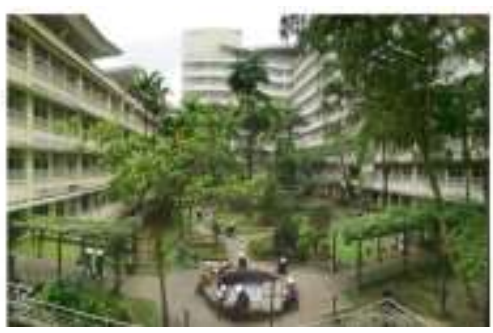

Fig. 1 (a) Site plan (Source: GDP Architects Sdn. Bhd.); (b) Ariel view of the hospital courtyard garden.

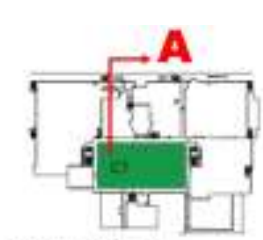

H1- LEVEL 2

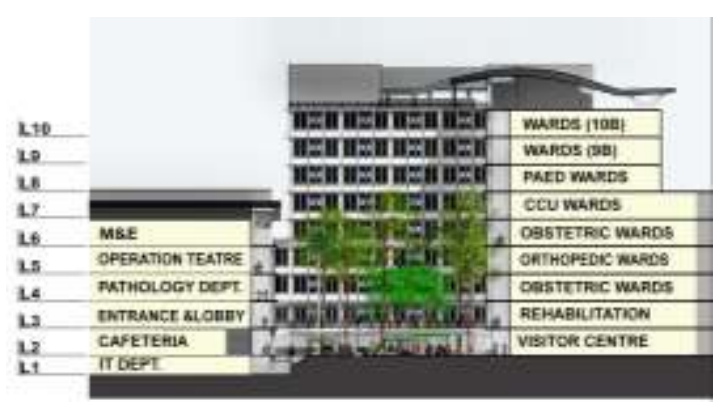

Fig. 2 Section A-A of the hospital courtyard garden (HCG)

\subsection{Ethical approval and data collection}

Ethical approval was obtained from the Medical Research Ethics committee (MREC), Ministry of Health Malaysia (MOH), and permission to gain access to the hospital courtyard was acquired from the hospital manager, before fieldwork. Face-to-face interviews survey were conducted with courtyard users in March 2018 at the same time as measurements of the microclimatic conditions in the HCG during a period of two weekdays and two weekends and from $9 \mathrm{am}$ to $5 \mathrm{pm}$ each day. A pilot test survey interview was conducted before starting the real fieldwork, which allowed for improvements to survey questions and adjustments to measuring instruments to guarantee accurate responses and robust data collection. The interview surveys technique was selected for this study to ensure a greater response rate and a decrease in the number of incomplete responses, commonly found in the selfadministrated survey technique.

Furthermore, the surveys were translated and conducted using the local language. Out of the 48 surveys, only 46 were fully completed among willing courtyard users sitting on benches in the hospital garden and therefore analysed for the purpose of this study. The 
respondents were recruited randomly from the courtyard users at the time of the field work. The majority of the 46 randomly chosen respondents consists of hospital visitors $(76 \%$; $n=35)$, followed by patients $(13 \% ; n=6)$ and staff $(11 \% ; n=5)$. A detailed distribution of the demographic data of the respondents is illustrated in Table 1. Hospital visitors were found to be the main users of the HCG in hospital H1 (Mat Idris, Sibley and Hadjri, 2018a).

Table 1: Percentage of distribution of demographic data ( $\mathrm{N}=46)$

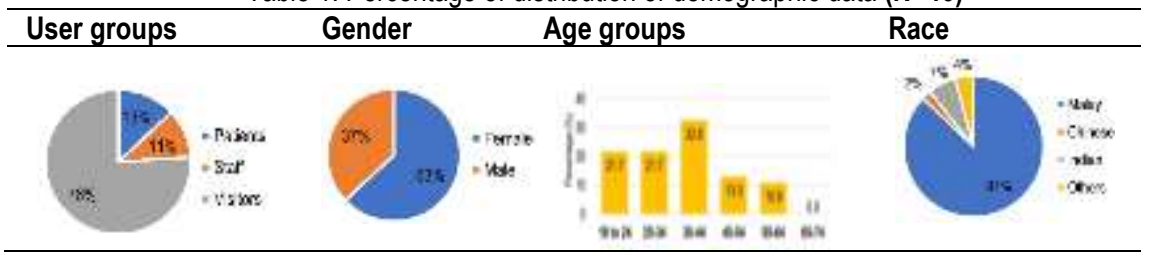

The environmental data of the HCG including air temperature $\left({ }^{\circ} \mathrm{C}\right)$, air relative humidity $(\%)$ and wind flow $(\mathrm{m} / \mathrm{s})$ were quantified via an AERCUS 3083 weather station fixed on a tripod at the height of 1.1 metres and located in the courtyard garden from $9 \mathrm{am}$ to $5 \mathrm{pm}$ per day. A portable environmental metre was also applied to record the actual air temperature and air relative humidity prior to the face to face interview surveys with the courtyard users. Furthermore, HOBO UA-002-64 were also used to measure and compare the air temperature in the hospital courtyard garden and the temperature outside the hospital (see Table 2).

Table $2:$ The equipment used to record the environmental data

AERCUS 3083 weather station The environmental meter HOBO UA-002-64

\subsection{Limitations of the study}

This study has a number of limitations with regard to the sampling. It is based on a relatively small sample of respondents $(\mathrm{N}=46)$ for the examined case study: Hospital $(\mathrm{H} 1)$ with visitors being the majority of users interviewed in the courtyard (Mat Idris, Sibley and Hadjri, 2018a). Not all visitors were willing to participate to the interview survey, as several of them were concerned about their sick family member, relative or friend who had been admitted to the hospital, following a medical emergency. Only those who were present in the HCG were approached to take part in the interview surveys. Moreover, the limited number of patients and staff who participated to the interview survey because they are among building users who rarely spend time in the HCG of the hospital (H1) (Mat Idris, Sibley and Hadjri, 2018a). Only the stationary users who were sitting on shaded benches in the garden had the time to be interviewed. Those who were crossing the courtyard garden were in a hurry and therefore 64 
not interviewed.

Future research should include a larger sample of respondents with a more equal distribution of users' groups (i.e. patients, staff and visitors) to be able to establish whether these groups have different responses and perceptions. Nonetheless, this relies on the accessibility of hospital courtyards by various users which in turns depends on the design configuration of the case study hospitals. Not all hospital courtyard gardens in Malaysian public hospitals will be necessarily accessible to large numbers of various types of building users that can be potential respondents to field survey. Observations carried out during this study indicates several HCGs in Malaysian public hospitals are either underused or not used at all. This is particularly the case when the management of the hospital decides to lock the access to courtyard gardens and when these are located in secluded areas of the building. Furthermore, respondents' thermal sensations in sunny areas of the courtyard were not recorded in this study as the majority of the participants preferred sitting in the shaded areas, avoiding direct exposure to the sun.

\subsection{Survey design and data analysis}

The design of the interview survey was informed by existing literature which emphasises the importance of examining outdoor gardens in healthcare facilities from the feedback of various building users (Cooper Marcus and Barnes, 1995; Whitehouse et al., 2001; Shukor, 2015). The survey questions were modified to include users' comfort sensations and perception of outdoor thermal conditions (e.g. air temperature; air movement; and air humidity) as demonstrated in Sharmin, Steemers and Matzarakis, (2015, p.743) and Nikolopoulou and Lykoudis (2006, p.1457). A seven-point ASHRAE scale and a 5-point Likert-type format were applied to collect the following data: (i) Users' perception on the courtyard setting (Question 8 -13); (ii) Users' experiences in the HCG (Question 20); (iii) Level of user' satisfaction with the provided facilities in the HCG (Question 21-22). The details of survey questions were provided in a previous paper (Mat Idris, Sibley and Hadjri, 2018b). Survey data based on Likert scale answers and multiple-choice responses were coded and analysed using SPSS.

\subsection{Results and discussion}

\subsection{Users' perception of the physical design of the HCG}

\section{i) What do users think about the landscape elements in the HCG?}

During the survey interviews ( $\mathrm{N}=46$ respondents), most courtyard users stated that all landscape elements (e.g. the water fountain, green plants, sitting areas, flowering plants, pedestrian walkways and green grass) were essential components of the HCG. This finding was in contrast to preceding research conducted in California, which demonstrated that the sound of running water was the utmost ideal landscape component amongst garden users (Whitehouse et al., 2001). However, in the Malaysian hospital courtyard setting, the highest 
frequencies of replies regarding the importance of features were recorded for flowering plants which were rated as 'very important' $(69.6 \%, n=32$, of total respondents). A small number of users reported that the water fountain was not much of significance to them $(13 \%, n=6)$ or not important $(4.3 \%, n=2)$ (See Fig. 3). The results from the survey highlighted that concern with child safety was the foremost reason why the respondents (i.e. visitors) felt that the courtyard water feature was not of much importance as it was perceived as a potential danger for young children who might fall into the water fountain. It is important to note that, the water feature in this $\mathrm{H} 1$ hospital was not working and there was no water inside it. However, if there is the accumulation of stagnant water after heavy rain, it will potentially attract mosquitoes, which are harmful to the hospital environment and its occupants. More than half of the respondents have however stated that the water feature is an important landscape feature as it can have a calming effect and relieve hospital stress.

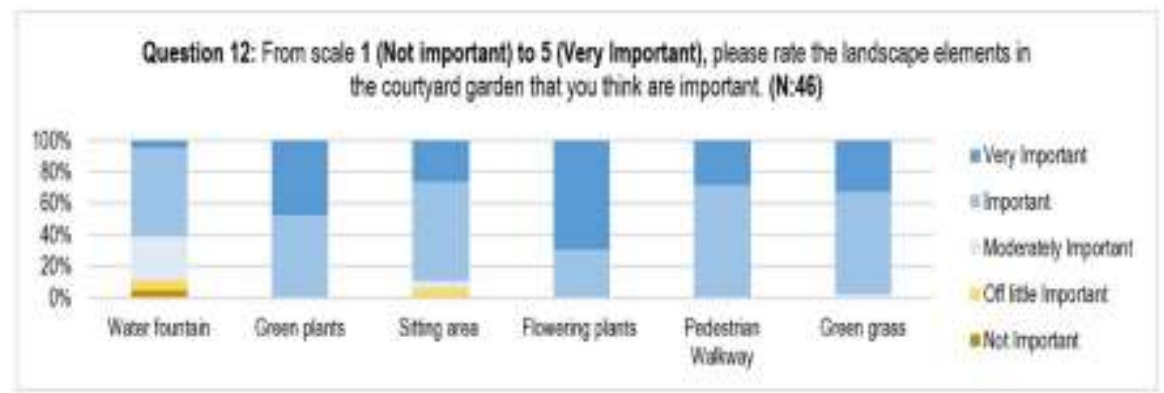

Fig. 3. Users' perception of the landscape elements in HCG

\section{ii) What do users think about the environmental design in the HCG?}

Questions regarding users' perception of the environmental design features the HCG were answered by all of 46 respondents. The vast majority of them ( $80 \%$ or more) perceived the courtyard shaded areas, the availability of daylight in the courtyard and its adjacent spaces, the breeze and fresh air and comfortable air temperature as all 'important' (+1) for them (See Fig. 4). Based on the frequencies of the survey responses, all respondents rated the availability of shaded areas as either 'important' or 'very important'. Cooper Marcus and Barnes (1995) emphasised that a number of design factors like poor vegetation, poor shading and seating reduced the utilisation of outdoor gardens in hospitals. Furthermore, Makaremi et al. (2012) and Pasha and Shepley (2013) also indicated that one of the factors that caused the reduction in use as well as the duration of use of outdoor gardens was users' dissatisfaction with the seating options and availability of shade. According to the study by Mat Idris, Sibley and Hadjri (2018a), the HCG at (H1) hospital offered a range of seating opportunities, all well-shaded areas by both the height of the building as well as the availability of large canopy trees. These created a comfortable place for people to spend extended periods in the HCG. Another crucial component of the HCG in (H1), which received a high rating of importance was the courtyard air temperature with $100 \%,(\mathrm{~N}=46)$ of the 
respondents reporting it to be 'important' or very 'important'.

Additionally, almost all respondents rated the availability of breeze and fresh air as 'important or 'very important' for the design of HCG. Only one respondent (an inpatient) indicated that breeze and fresh air were 'not important' to her as she preferred a warmer environment in the HCG to escape from the cool air-conditioned hospital ward. This respondent also felt uncomfortable with the breeze that flowed into the courtyard as she preferred a less windy environment. The role of the courtyard to provide daylight to the indoor spaces was not perceived as important by a small fraction of the respondents $(15 \%, n=7)$ who reported that this was of little or not important.

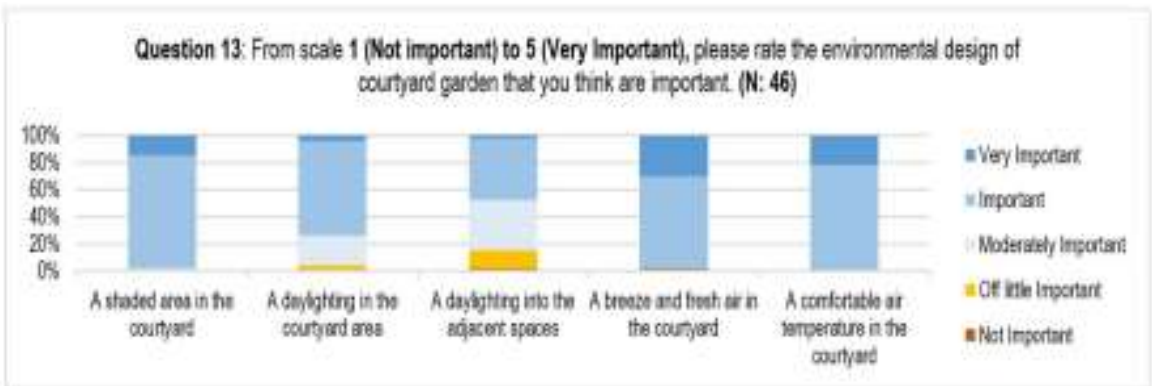

Fig. 4. Graph percentage of users' perception of the environmental design of the HCG

\subsection{Users perception of the microclimatic conditions of HCG}

Malaysia is located in a tropical climate zone with a substantial high density of solar radiation, high daily air temperature, high humidity, extreme rainfall and low wind flow (Makaremi et al., 2012; Malaysian Meteorological Department, 2012). Outdoor thermal comfort could be influenced by many environmental factors such as air temperature, wind flow and air humidity (Ahmed, 2003; Sharmin, Steemers and Matzarakis, 2015). Moreover, other parameters including cultural, personal and psychological factors also influenced the public's thermal sensation (Nikolopoulou and Lykoudis, 2006; Sharmin and Steemers, 2018).

\section{i) How does the temperature inside the HCG differ from the temperature outside the hospital?}

The microclimatic parameters such as air temperature $\left({ }^{\circ} \mathrm{C}\right)$, wind flow $(\mathrm{m} / \mathrm{s})$ and air humidity (\%) of the courtyard garden in (H1) hospital were measure on-site via AERCUS 3083 weather station during the field survey from $9 \mathrm{am}$ to $5 \mathrm{pm}$ to understand how these measurements relate to users' thermal sensations in the HCG. The average temperature recorded during the field survey was $29.4^{\circ} \mathrm{C}$ whereas the recorded relative humidity was $69.1 \%$. According to the Beaufort scale, the average wind speed was $1.3 \mathrm{~m} / \mathrm{s}$, which was light air (at a height of 1.1 metres) (see Table 3).

Table 3: Measurements of microclimatic conditions in the HCG during survey days Summary of the microclimatic conditions during survey days between $9.00 \mathrm{am}$ to $5.00 \mathrm{pm}-4$ days 
Mat Idris, M., \& Sibley, M. / Asian Journal of Environment-Behaviour Studies (ajE-Bs), 4(13) May / Aug 2019 (pp.60-76)

\begin{tabular}{lllll}
\hline Environmental data & Max & Min & Mean & SD \\
\hline Air temperature, $\left({ }^{\circ} \mathrm{C}\right)$ & 32.7 & 26.3 & $\mathbf{2 9 . 4}$ & 1.2 \\
\hline Relative humidity, $(\%)$ & 90 & 50 & 69 & 6.85 \\
\hline $\begin{array}{l}\text { Wind speed, }(\mathrm{m} / \mathbf{s}) \\
\text { (Beaufort scale) }\end{array}$ & 3.19 & 0.31 & $\mathbf{1 . 3}$ & 0.81 \\
\hline
\end{tabular}

The air temperature in the courtyard garden and outside the hospital was recorded with HOBO UA-002-64 from 9 am to $5 \mathrm{pm}$ on 10 March 2018. The findings revealed that the overall air temperature in the courtyard garden was marginally inferior to that recorded outside the hospital building with an average temperature difference of $2.0^{\circ} \mathrm{C}$. The temperature recorded at $1 \mathrm{pm}$ indicated that the air temperature was $27.3^{\circ} \mathrm{C}$ in the $\mathrm{HCG}$ and $31.4^{\circ} \mathrm{C}$ outside the hospital with a temperature difference of $4.1^{\circ} \mathrm{C}$ (see Fig. 5). This implies that the HCG formed a cooler microclimate that provided a comfortable environment for people to sit and spend time in the courtyard garden.
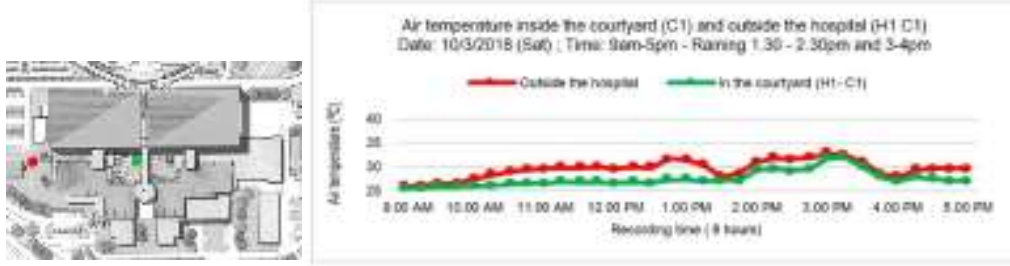

Fig. 5. Air temperature inside the courtyard (C1) and outside the hospital (H1 C1). Date: 10/3/2018 (Sat) ; Time: 9am-5pm. Note: Raining at 1.30pm - 2.30pm and 3.30pm-4pm

\section{ii) What are users' thermal sensation votes (TSV) and perception of air temperature in the HCG}

Respondents' thermal sensation was quantified via an ASHRAE 7-point scale: cold (-3), cool $(-2)$, slightly cool $(-1)$, neutral $(0)$, slightly warm $(+1)$, warm $(+2)$ and hot $(+3)$ to understand courtyard users' perceptions of air temperature in the HCG. The neutral temperature, a term initially proposed by Humpreys (1975), is an alternative approach to evaluate the thermal sensation (Nikoloupoulou and Lykoudis, 2006). Participants voted for neutral ' 0 ' to specify that they neither felt warm or cold (ibid). Based on the findings of the survey, more than half of the respondent $(54.4 \%, n=14$ males, $n=11$ females) voted for 'neutral' (0). This revealed that they felt thermally comfortable within the outdoor neutral temperature, which ranged between $26.2^{\circ} \mathrm{C}$ and $32.7^{\circ} \mathrm{C}$ with an average neutral temperature of $29.2^{\circ} \mathrm{C}$ (see Fig. 6 (a) and (b)). In a study carried out in a semi-outdoor area in a food centre building in Singapore, within a similar tropical climate, Song (2006) demonstrated that the acceptable temperature range was between $23.0^{\circ} \mathrm{C}$ and $31.2^{\circ} \mathrm{C}$; the neutral temperature was $27.2^{\circ} \mathrm{C}$ (Yang, Wong and Jusuf, 2013). The finding of this study was in agreement with another previous study performed by Ahmed (2008), in a tropical climate country, which reported that people who wore summer clothing and engaged in outdoor sedentary activities were thermally 
comfortable in temperatures lower than $34^{\circ} \mathrm{C}$ with an average air temperature ranging between $28.5^{\circ} \mathrm{C}$ and $32^{\circ} \mathrm{C}$.
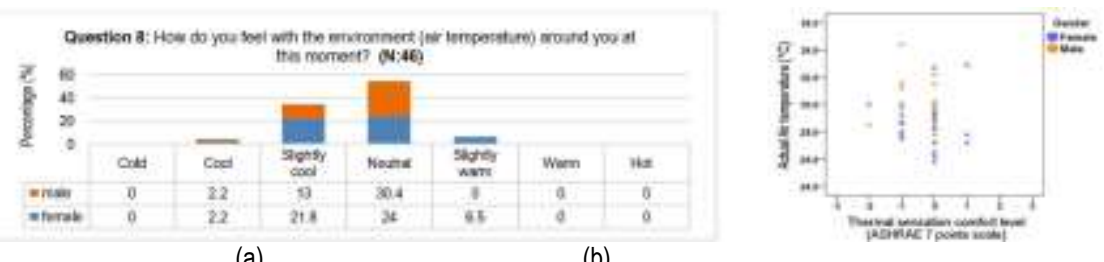

(a)

(b)

Fig. 6. (a) Air temperature thermal sensation votes (ASHRAE 7 point scale); (b) Variation of thermal sensation votes (TSV), in relation to actual air temperature

The results of this current study reveal that about one-third of the respondents $(34.8 \%$, $\mathrm{n}=10$ females, $\mathrm{n}=6$ males) perceived the temperature in the courtyard as 'slightly cool' and two respondents perceived it as 'cool' ( $4.3 \%, n=1$ female; $n=1$ male). The findings also reveal that a smaller percentage reported a sensation of being 'slightly warm as reported by 3 female respondents $(6.5 \%$ of the respondents). None of the respondents reported being either 'warm' or 'hot' in the courtyard garden (See Fig. 4 (a)). A number of respondents are likely to express their thermal sensation in marginally extreme from other respondents because of the variation in many personal factors including age, diverse varieties of clothing, and metabolism rate. The present study reveals that there was no difference in the reported thermal sensations of respondents of a different gender. This has also been demonstrated by previous studies such as Spagnolo and de Dear (2003), Makaremi et al. (2012) and Kruger and Drach (2017). A previous study carried out in Brazil in 2013 demonstrated that respondents' age difference was a significant factor influencing their thermal sensation. The elderly (over 55-years old) were found to be more vulnerable to greater outdoor temperatures (Pantavou et al. 2013).

\section{iii) How do users feel about wind flow and air humidity in the HCG?}

All respondents $(\mathrm{N}=46)$ who spent time in the HCG were asked about their perception of wind flow and air humidity in the hospital courtyard. The wind sensation varied from stale (-2) to too much wind (+2). Within the wind flow ranged between $0.31 \mathrm{~m} / \mathrm{s}$ (light air) to $3.19 \mathrm{~m} / \mathrm{s}$ (light breeze), $28.3 \%$ ( $n=13$ (8 females and 5 males)) of the respondents voted 'OK' $(0)$ in which they felt comfortable with the wind flow at the site. 30.5\% ( $n=14$ ( 9 females and 5 males) of the respondents reported their wind sensation as 'windy' (+1) and 'too much wind' (+2). Less than half of the respondents $(41.2 \%, n=19)$ felt 'little wind' $(-1)$ and 'stale' $(-2)$ (See Fig. 6 (a)). Moreover, the findings revealed that most of the respondents who spent time sitting in the HCG felt the wind in the enclosed HCG. The light air speed in the HCG recorded during the day of the field surveys varied between $0.31 \mathrm{~m} / \mathrm{s}$, and $1.3 \mathrm{~m} / \mathrm{s}$ improved heat transfer between the air and the human body, thus elevated the cooling process of the human body. Consequently, $93 \%$ of the respondents stated that they felt comfortable even though the air temperature was high. This is mainly due to the existence of a light breeze in the HCG. 
This study inferred that the design of the hospital roof in a Curve V-shape contributed to bringing the wind flow down into the courtyard garden. This was also reported in a preceding study of a shophouse in Malaysia with a V-shape roof configuration (Kubota et al., 2017). Furthermore, outsized canopy trees and vegetations in the courtyard garden improved its microclimatic conditions as it offered shade and therefore diminished the amount of solar radiation into the courtyard and offered a comfortable environment (De Abreu-Harbich, Labaki and Matzarakis, 2015; Ghaffarianhoseini, Berardi and Ghaffarianhoseini, 2015). As a result, this encouraged many users to spend time sitting in the HCG (Mat Idris, Sibley and Hadjri, 2018a).

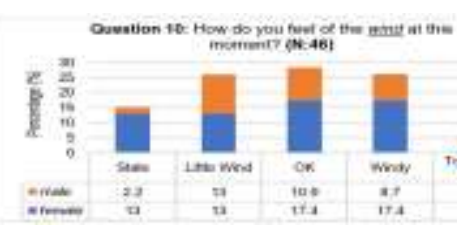

(a)

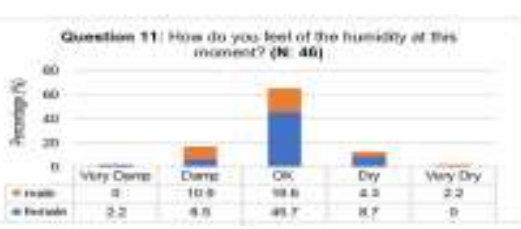

(b)

Fig. 7. (a) Wind sensation votes; (b) Humidity sensation votes

Regarding the humidity sensation votes, almost two-thirds of the respondents $(65.2 \%$, $\mathrm{n}=30$ (21 females and 9 males) reported feeling comfortable with the air humidity in the HCG which ranged between $60.5 \%$ to $85 \%$ throughout the survey days (9am-5pm). Only $15.2 \%$ of the respondents ( $n=4$ females; 3 males) reported a sensation of 'Dry' ( +1$)$ and 'Very Dry' $(+2)$, while $19.6 \%$ of the respondents ( $n=4$ females; 5 males) voted for 'Damp' ( -1$)$ and 'Very Damp' (-2) (See Fig. 7 (b)).

\subsection{How do users feel while spending time in the HCG?}

The respondents were also asked about their feelings while spending time in the HCG. The respondents were enquired to rate their feelings on a 5-point Likert scale. Questions ranged from 'Strongly Disagree' (-2) to 'Strongly agree' (+2) (See Fig. 8). The survey findings revealed that the majority of respondents indicated positive changes to their mood while being in the HCG. Additionally, most of the respondents voted 'agree' (+1), indicating that they felt more relaxed and less stressed $(93.5 \%, n=43)$, more refreshed and rejuvenated $(87.0 \%, n=40)$, felt pleased, positive and better $(84.8 \%, n=39)$, felt calmer and were able to think positively $(84.8 \%, n=39)$, comfortable $(84.8 \%, n=39)$, and safe $(82.6 \%, n=38)$. Additionally, more than half of the respondents $(58.7 \%, n=27)$ voted 'agree' $(+1)$ that being in the HCG made them feel highly associated to their religious or spiritual self. On the other hand, only very few disagreed $(4.3 \%, n=2)$. This result was in agreement with a previous study which demonstrated that human interaction with the natural environment (i.e. plants, flower, sound of water, fresh air, natural lighting) had a positive impact on moods of those who visited and viewed the garden (Cooper Marcus and Barnes, 1995; Whitehouse et al., 2001; Sherman et al., 2008; Shukor, 2015). 


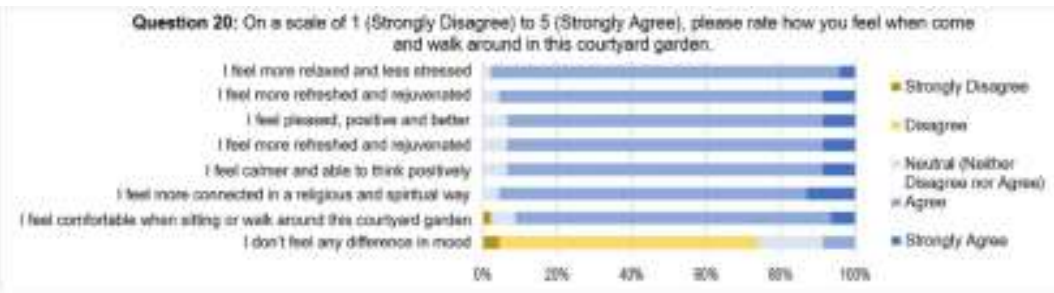

Fig. 8. Users' experiences of the Hospital Courtyard Garden

\subsection{Are users satisfied with the environmental design of HCG?}

More than $80 \%$ of the respondents expressed their satisfaction with all physical characteristics of the HCG (i.e. accessibility, visibility, wayfinding, design and planning) when enquired to vote from slightly satisfied $(0)$, satisfied $(+1)$ to very satisfied $(+2)$ (See Fig. 9 and Table 4). All respondents $(100 \%, n=46)$ expressed being satisfied with the location of the courtyard adjacent to the cafeteria and more than $80 \%$ of the respondents expressed satisfaction with its accessibility and visibility (i.e. accessibility for wheelchair users $(86.9 \%$, $\mathrm{n}=40)$, accessibility from main lobby to courtyard area $(82.6 \%, n=38)$, accessibility to diverse departments $(95.7 \%, n=44)$, entrances of courtyard garden $(91.3 \%, n=42)$, visibility of the courtyard garden from the nearby space $(95.7 \%, n=44)$ and wayfinding to the courtyard garden $(93.5 \%, \mathrm{n}=43)$. Very few respondents expressed dissatisfaction with the layout and planning of the HCG $(17.4 \%, n=8)$, accessibility from the main lobby to the courtyard garden $(17.4 \%, n=8)$ and accessibility of the courtyard for wheelchair users $(13.1 \%, n=6)$. Nonetheless, almost half of the respondents $(47.8 \%, n=22)$ expressed their dissatisfaction with the landscape elements (i.e. water fountain, categories of herbs garden, seating and choice of plantings). Moreover, $41.3 \%(n=19)$ were dissatisfied with the colour of the wall around the HCG, which slowly began to fade.

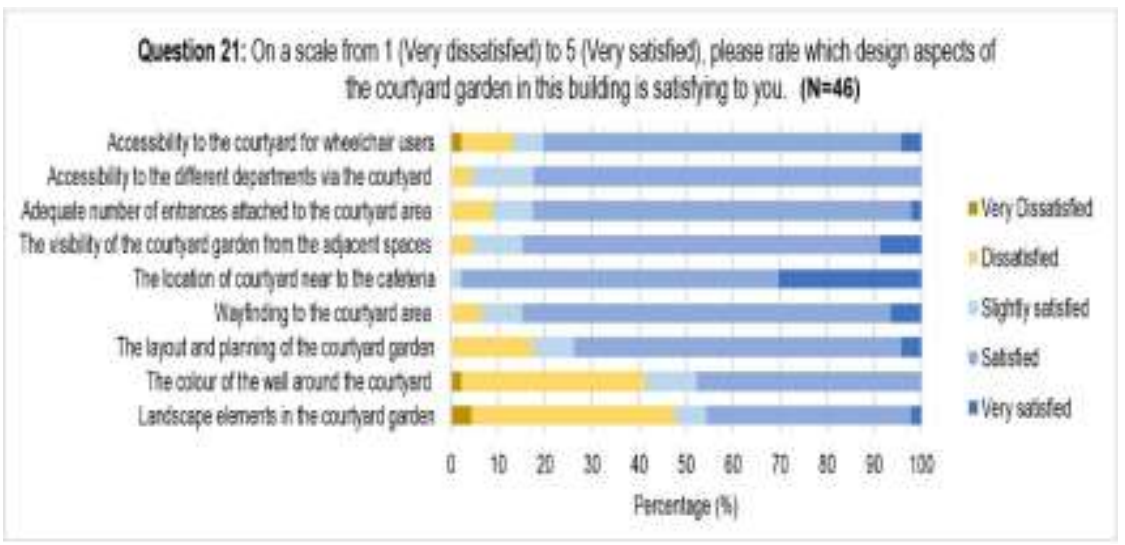

Fig. 9. Level of satisfaction with the environmental design of (H1) hospital courtyard garden 
Table 4: Level of satisfaction of the environmental design of the HCG

\begin{tabular}{|c|c|c|c|c|}
\hline $\begin{array}{l}\text { Environmental } \\
\text { design aspects }\end{array}$ & Images & & Satisfied & Dissatisfied \\
\hline $\begin{array}{l}\text { Provide easy } \\
\text { access for the } \\
\text { wheelchair } \\
\text { users }\end{array}$ & & $\frac{6}{25}$ & $86.9 \%$ & $13.1 \%$ \\
\hline $\begin{array}{l}\text { Provide an } \\
\text { adequate } \\
\text { number of the } \\
\text { entrance to the } \\
\text { HCG }\end{array}$ & & 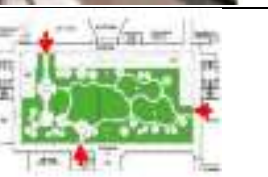 & $91.3 \%$ & $8.7 \%$ \\
\hline $\begin{array}{l}\text { Provide location } \\
\text { near to the } \\
\text { cafeteria }\end{array}$ & & & $100 \%$ & - \\
\hline $\begin{array}{l}\text { Provide view to } \\
\text { the HCG }\end{array}$ & & $\begin{array}{l}\text { View to the HCG from } \\
\text { the main lobby at floor } \\
3 \text {. }\end{array}$ & $95.7 \%$ & $4.3 \%$ \\
\hline $\begin{array}{l}\text { Provide } \\
\text { wayfinding } \\
\text { (Signage to the } \\
\text { HCG) }\end{array}$ & & $\begin{array}{l}\text { The signage indicates } \\
\text { the location of the herb } \\
\text { garden. }\end{array}$ & $93.5 \%$ & $6.5 \%$ \\
\hline $\begin{array}{l}\text { Maintain the } \\
\text { colour of the } \\
\text { wall }\end{array}$ & & $\begin{array}{l}\text { The colour of the wall } \\
\text { faded, and black stains } \\
\text { appear on the concrete } \\
\text { slab. The wall needs to } \\
\text { be cleaned and painted. }\end{array}$ & $58.7 \%$ & $41.3 \%$ \\
\hline $\begin{array}{l}\text { Provide } \\
\text { appropriate } \\
\text { landscape } \\
\text { elements }\end{array}$ & 10 & $\begin{array}{l}\text { The water fountain is } \\
\text { provided in the HCG. } \\
\text { However, it is not } \\
\text { functioned. It needs to } \\
\text { be fixed. } \\
\text { Several herb plants } \\
\text { were lack of care. } \\
\text { The planting labelled } \\
\text { need to be fixed. }\end{array}$ & $52.2 \%$ & $47.8 \%$ \\
\hline
\end{tabular}




\subsection{Conclusion}

This study has investigated users' (i) perceptions; (ii) experiences and, (iii) satisfaction level with respect to the design quality of a central courtyard garden in a public hospital in Malaysia. The results of this study revealed that:

(i) More than half of the respondents $(54.4 \%, n=25)$ stated a comfortable sensation with the outside air temperature while sitting in the HCG. Measurements of air temperature outside the hospital and inside the HCG demonstrated that the average air temperature inside the courtyard garden was below that of outside the hospital by $2.0^{\circ} \mathrm{C}$. The temperature recorded at $1 \mathrm{pm}$ on $10^{\text {th }}$ of March 2018 revealed that the air temperature was $27.3^{\circ} \mathrm{C}$ in the $\mathrm{HCG}$ compared to a temperature of $31.4^{\circ} \mathrm{C}$ outside the hospital with a significant temperature difference of $4.1^{\circ} \mathrm{C}$. It is clear that the central courtyard provided a cooler and comfortable microclimate, which was attractive to users (Mat Idris, Sibley and Hadjri, 2018a).

(ii) The majority of the respondents reported that spending time in the courtyard resulted in them feeling more relaxed and less stressed $(93.5 \%, \mathrm{n}=43)$, more refreshed and rejuvenated $(87.0 \%, n=40)$, pleased, positive and better $(84.8 \%, n=39)$, calmer and able to think positively $(84.8 \%, n=39)$, comfortable $(84.8 \%, n=39)$, and safe $(82.6 \%, n=38)$.

(iii) More than $80 \%$ of the respondents in the $\mathrm{H} 1$ hospital stated that they were satisfied with the design and planning of the HCG. This includes accessibility for wheelchair users $(86.9 \%, n=40)$, accessibility from main lobby to HCG $(82.6 \%, n=38)$, accessibility to different departments $(95.7 \%, n=44)$, accessibility to the HCG $(91.3 \%, n=42)$, visibility of the HCG from adjacent spaces $(95.7 \%, n=44)$ and wayfinding to the $\mathrm{HCG}(93.5 \%, \mathrm{n}=43)$. Nonetheless, almost half of the respondents were dissatisfied with the landscape elements $(47.8 \%, n=22)$ and the colour of the wall around the HCG $(41.3 \%(n=19)$.

This study has provided a new understanding of how various physical and environmental attributes of a central hospital courtyard garden are experienced and perceived by hospital users within hospital visitors. The results of both face to face survey interviews and environmental measurements, as well as the respondents' expressed levels of satisfaction, have provided the first insight into what architects and landscape architects should take into consideration when designing future hospitals in a tropical climate with a large central courtyard garden. The results also provide useful information to hospital providers and managers as to what improvements could be made in existing hospital courtyard gardens to enhance their quality and provide a more convenient and healthier environment for the end users.

\section{Acknowledgement}

We are very grateful to the Director General of Health Malaysia, Ministry of Health Malaysia $(\mathrm{MOH})$ for giving the approval to submit this article for publication. We would also like to thank the manager of the hospital $(\mathrm{H} 1)$ for granting their permission to access and conduct the study at their hospital. Thanks to the Ministry of Education in Malaysia and the Science Islamic University of Malaysia (USIM) for providing funding throughout this ongoing study. This study has no conflict of interest. 


\section{References}

Ahmed, K. S. (2003). Comfort in urban spaces: defining the boundaries of outdoor thermal comfort for the tropical urban environments. Energy and Buildings, 35(1), 103-110.

Almhafdy, A., Ibrahim, N., Ahmad, S.S. and Yahya, J. (2013). Analysis of the Courtyard Functions and its Design Variants in the Malaysian Hospitals. Procedia-Social and Behavioral Sciences, 105, 171-182.

Bordass, B., \& Leaman, A. (2005). Making feedback and post-occupancy evaluation routine 1: A portfolio of feedback techniques. Building Research \& Information, 33(4), 347-352.

Butterfield, A. (2014). Resilient places? The healthcare gardens and the Maggie's Centres (Doctoral dissertation, University of the Arts London and Falmouth University).

Cooper Marcus, C., and Sachs, A.N. (2014) Therapeutic Landscapes. An Evidence-Based Approach to Designing Healing Gardens and Restorative Outdoor Spaces. New York: John Wiley \& Sons

Cooper Marcus, C., and Barnes, M. (1995). Gardens in healthcare facilities: Uses, therapeutic benefits, and design recommendations. Concord, CA: Center for Health Design.

Cooper Marcus, C., and Francis, C. (1998). People Places: Design Guidelines for Urban Open Space, 2nd ed. John Wiley \& Sons, Inc., Toronto

Davis, B. E. (2011). Rooftop hospital gardens for physical therapy: A post-occupancy evaluation. HERD: Health Environments Research \& Design Journal, 4(3), 14-43.

De Abreu-Harbich, L. V., Labaki, L. C., and Matzarakis, A. (2015). Effect of tree planting design and tree species on human thermal comfort in the tropics. Landscape and Urban Planning, 138, 99-109.

Ghaffarianhoseini, A., Berardi, U., and Ghaffarianhoseini, A. (2015). Thermal performance characteristics of unshaded courtyards in hot and humid climates. Building and Environment, 87, 154-168.

Ghazali, R., \& Abbas, M. Y. (2012). Natural environment in paediatric wards: Status and implications. ProcediaSocial and Behavioral Sciences, 68, 173-182.

Hadjri, K., and Crozier, C. (2009). Post-occupancy evaluation: Purpose, benefits and barriers. Facilities, 27(1/2), 21-33.

Ibrahim, F., Harun, W. M. W., Samad, M. H. A., and Kamaruddin, W. N. W. S. W. (2015). The Physical Attributes of Healing Garden for a Century Old Healthcare Premises. International Transaction Journal of Engineering, Management, \& Applied Sciences \& Technologies, 6(2), 47-59.

Kruger, E. L., and Drach, P. (2017). Identifying potential effects from anthropometric variables on outdoor thermal comfort. Building and Environment, 117, 230-237.

Kubota, T., Zakaria, M. A., Abe, S., \& Toe, D. H. C. (2017). Thermal functions of internal courtyards in traditional Chinese shophouses in the hot-humid climate of Malaysia. Building and Environment, 112, 115-131.

Makaremi, N., Salleh, E., Jaafar, M. Z., \& GhaffarianHoseini, A. (2012). Thermal comfort conditions of shaded outdoor spaces in hot and humid climate of Malaysia. Building and environment, 48, 7-14. 
Mastor, S. H., and Ibrahim, N. (2010). Post occupancy evaluation practices: a procedural model for a successful feedback. In Proceedings of the CIB 2010 World Congress, Salford Quays, United Kingdom (pp. 10-13).

Mat Idris, M., Sibley, M., and Hadjri, K. (2018a). Investigating Space Use Patterns in a Malaysian Hospital Courtyard Garden: Lessons from real-time observation of patients, staff and visitors. Environment-Behaviour Proceedings Journal, 3(8), 32-45.

Mat Idris, M., Sibley, M., and Hadjri, K. (2018b). Users' perceptions, experiences and level of satisfaction with the quality of a courtyard garden in a Malaysian public hospital. Environment-Behaviour Proceedings Journal, 3(9), 63-73.

Mohd Nawawi, N. (2011) Brief insights on the Post Occupancy Evaluation (POE) of Malaysian public healthcare facilities. In: Architectural Design Practice and Projects. IIUM Press, Kuala Lumpur, 49-60.

Naderi, J. R., \& Shin, W. H. (2008). Humane design for hospital landscapes: A case study in landscape architecture of a healing garden for nurses. HERD: Health Environments Research \& Design Journal, 2(1), 82119.

Nawawi, A. H., \& Khalil, N. (2008). Post-occupancy evaluation correlated with building occupants' satisfaction: An approach to performance evaluation of government and public buildings. Journal of Building Appraisal, 4(2), 5969.

Nikolopoulou, M., \& Lykoudis, S. (2006). Thermal comfort in outdoor urban spaces: analysis across different European countries. Building and environment, 41(11), 1455-1470.

Pantavou, K., Theoharatos, G., Santamouris, M., \& Asimakopoulos, D. (2013). Outdoor thermal sensation of pedestrians in a Mediterranean climate and a comparison with UTCI. Building and Environment, 66, 82-95.

Pasha, S. (2013). Barriers to garden visitation in children's hospitals. HERD: Health Environments Research \& Design Journal, 6(4), 76-96.

Pasha, S., \& Shepley, M. M. (2013). Research note: Physical activity in pediatric healing gardens. Landscape and Urban Planning, 118, 53-58.

Preiser, W. F. E. (1995). Post-occupancy evaluation: How to make buildings work better. Facilities, 13(11), 19-28. Sachs, N.A. (1999). The therapeutic value of outdoor space in psychiatric healthcare facilities. University of California, Berkeley.

Said, I., Salleh, S. Z., Bakar, M. S. A., \& Mohamad, I. (2005). Caregiver' Evaluation on Hospitalized Children's Preferences Concerning Garden and Ward. Journal of Asian Architecture and Building Engineering, 4(2), 331-338.

Sharmin, T., Steemers, K., \& Matzarakis, A. (2015). Analysis of microclimatic diversity and outdoor thermal comfort perceptions in the tropical megacity Dhaka, Bangladesh. Building and Environment, 94, 734-750.

Sharmin, T., \& Steemers, K. (2018). Effects of microclimate and human parameters on outdoor thermal sensation in the high-density tropical context of Dhaka. International journal of biometeorology, 1-17.

Sherman, S. A., Varni, J. W. Ulrich, R. S. \& Malcarne, V. L. (2005). 'Post-occupancy evaluation of healing gardens in a paediatric cancer centre', Landscape and Urban Planning, 73(2-3), 167-183.

Shukor, S. F. A. (2012). Restorative Green Outdoor Environment at Acute Care Hospitals. Case Studies in Denmark. Forest \& Landscape Research, (57-2012). 
Spagnolo, J., \& De Dear, R. (2003). A field study of thermal comfort in outdoor and semi-outdoor environments in subtropical Sydney Australia. Building and environment, 38(5), 721-738.

Toone, T. L. (2008). Effects of Healing Garden Use on Stress Experienced by Parents of Patients in a Pediatric Hospital (Master dissertation, Texas A \& M University).

Whitehouse, S., Varni, J. W., Seid, M., Cooper-Marcus, C., Ensberg, M. J., Jacobs, J. R. \& Mehlenbeck, R. S. (2001). 'Evaluating a Children's Hospital Garden Environment: Utilization and Consumer Satisfaction', Journal of Environmental Psychology, 21(3), 301-314.

Yang, W., Wong, N. H., \& Jusuf, S. K. (2013). Thermal comfort in outdoor urban spaces in Singapore. Building and Environment, 59, 426-435. 